\title{
Analysis of a Moodle-Based Training Program about the Pedagogical Content Knowledge of Evolution Theory and Natural Selection
}

\author{
Panagiotis K. Stasinakis ${ }^{1} \&$ Michail Kalogiannnakis ${ }^{1, *}$ \\ ${ }^{1}$ Faculty of Education, Department of Preschool Education, University of Crete, University Campus - Gallos, Crete, \\ Greece \\ *Correspondence: Faculty of Education, Department of Preschool Education, University of Crete, University \\ Campus - Gallos, P.C. 74100, Rethymno - Crete - Greece. Tel: 30-283-107-7889. E-mail: mkalogian@edc.uoc.gr
}

Received: November 18, 2016

Accepted: Decmeber 15, 2016 Online Published: January 5, 2017

doi:10.5430/wje.v7n1p14

URL: http://dx.doi.org/10.5430/wje.v7n1p14

\begin{abstract}
In this study we aim to find out whether a training program for secondary school science teachers which was organized based on the model of Pedagogical Content Knowledge (PCK), could improve their individual PCK for a specific scientific issue. The Evolution Theory (ET) and the Natural Selection (NS) were chosen as the scientific issues of interest. Both of them are fundamental in biology teaching, especially the ET which can be taught as a unifying theory of biology. The individual PCK of teachers can be improved by strengthening its components: knowledge, pedagogy and managing the context. The principals and content of the seminar were decided based on the results of another study among Greek teachers for the characteristics of their PCK about ET, NS and Nature Of Science (NoS). The seminar involved 16 secondary school teachers. We found that all trainees improved their individual PCK and felt adequate to teach more effectively the ET and the NS to their students. All participants through the activities they performed, moved to a more constructive and learner-centered teaching style compare to what they used to do before the training program.
\end{abstract}

Keywords: pedagogical content knowledge (PCK); evolution teaching; distant training programme; Moodle; professional development (PD)

\section{Introduction}

Training constitutes an educational process that extends beyond the initial education, aims at people who are already in a particular professional context. Adult learners participate in a training program by given intentions and a set of experiences. With a sense of perspective and self-determination, which gives the training a more complex nature and require a well-designed process, aiming at a particular purpose. Nowadays, the increasingly widespread perception of teachers about their role as professionals is one of the critical factors that drives them to participate in training programs, to improve their professional status for their professional development.

Teachers' training is a key requirement for a successful education system. Educational systems that were created with the belief that the curriculum is automatically ready to be taught because of scientific competence of the teacher, failed (McDermott, 1991). The connection with school practice, the knowledge and the skills of trainers, the need for increased coherence and consistency between the training process and the training format, the internal mobilization activation based on the result of an action and not a theoretical construction - are critical parameters, which are often not taken into account when designing training programs. These parameters were determining factors in the shaping of the proposed e-learning training program for secondary education teachers, in this research.

Science teachers' training on issues which emphasizing on teaching strategies and content knowledge, contribute to their professional development (Paik et al., 2011). Seems to be a gap between research and school practice, since teachers ignore scientific research and researchers are based on data and proposals which sometimes ignore the school practice. As supported by Treagust \& Duit (2009) the gap between what is necessary from the perspective of researchers and what can be implemented by teachers, has been increased. This gap can be declined by teachers' 
education, so teachers to learn about the results of contemporary research and in collaboration with the research community to be helped to improve their teaching practice.

\section{Theoretical Framework}

\subsection{Teacher Training}

In several European countries, the pre-service teacher's education is academic and does not associate with the practical role which he/she faces in the school context. Several European countries have accepted a model of continuous and lifelong professional development of the teacher, designing properly their educational policy, while others bring to the planning or discussion (Euridice, 2004). The goal of lifelong education (effective introductory and subsequent in-service training programs) has given a new dimension in teaching and learning because the skills and roles required from teachers exceed the limits of their undergraduate studies.

Teachers through training, develop a personal and professional level, by participating in local and global community networks. They learn to choose and use, from a variety of ICT (Information and Communication Technologies) tools, those that are more effective in relation to the objectives that have been set (Akbulut, Kesim \& Odabasi, 2007). Moreover, teachers can be trained about ethical and legal issues related to intellectual property and transmit the responsible use of ICT to their students.

In modern pedagogical approaches the teachers of natural sciences should take into account all the perceptions of students and involve them in a variety of activities that create incentives for learning, such as: to encourage active learning, to promote inquiring study, to encourage dialogue-justification-analysis-interaction, to cultivate search-critical skills of information processing (Osborne, 2003). Research shows a significant variation in how each teacher incorporates ICT in teaching, both in content as well as to the objectives he/she wants to achieve. Teachers, who are oriented to traditional practices in their own teaching, face difficulties to adopt ICT and when they attempt to do so it becomes on the basis of their pedagogical orientation, unlike to teachers who adopt student-centered pedagogical attitude (Hermans, Tondeur, Braak \& Valcke, 2008).

For the Greek educational system, the satisfaction of teachers from participating in trainings can be called moderate as the contribution of content and methodology of training programs on specific issues of school practice with emphasis on the use of ICT (Kalogiannakis, 2010).

\subsection{Pedagogical Content Knowledge (PCK)}

The Pedagogical Knowledge Content (PCK), from its initial introduction by Shulman (Shulman, 1987) has been transformed, enriched and interpreted in several ways (Van Dijk \& Kattmann, 2007; Loughran, Mulhall \& Berry, 2008). These modifications make PCK "unclear" both in its boundaries and in the way of its development. However, its position in the international literature is given, as a powerful tool in the teaching of Science and teacher training.

Research shows that teachers with high PCK levels, have resulted achieving better performance of their students (Abell, 2007) indicating that a successful teacher education should aim to develop PCK. Moreover, PCK according to Shulman (1987) is the knowledge teachers hold and the answer to the following question "What is it that a teacher knows and can do, that the expert on the subject taught by a teacher, regardless his/her capability, is not able to understand and to do" (Berry, Loughran \& Driel, 2008).

\subsection{Teachers' Distance Learning}

Traditional teaching methods are not competitive anymore, so we need to provide innovative tools for the forthcoming challenges. Lifelong learning based on the distance education with the use of ICT seems to be very important. Nowadays researchers explore new definitions of lifelong learning, they recognize the fundamental role of informal learning communities, and propose to governments considerations for compulsory education and the further development of technologies used in information and communication (Kendall, 2005).

The promises of e-learning and pedagogical innovations have not been succeeded (Salmon, 2005). A gap among the mere supply of information and the actual knowledge-building and training have been created (Barbera, 2004). Laurillard (2001) notes that student's direct experience of the world should be related to an understandable set of academic concepts and processes, and argues that university teaching is basically a theoretically activity in order to change students the option they experience the real world. As a result, Laurillard (2001) points that because of the second-order character of the academic knowledge (based on symbolic representation, such as language, mathematical symbols, etc), it requires interpretation so that the mediation is to have a positive effect. 
According to Sang, Valcke, van Braak \& Tondeur (2010), attitudes and perceptions of the teachers towards ICT and their stress on the use of ICT which through experience can be reduced or / and their systematic training, are key factors that hinder the application of ICT in the educational process. ICTs provide the opportunity to support the achievement of learning results when follow the goals of the curriculum (Rutten, van Joolingen, \& van der Veen, 2012). For science teaching, ICT contribute positively to the teaching and learning process; higher contribution is achieved when utilized with pedagogical documentation in an integrated learning framework by giving an active role to the students (Jimoyiannis, 2010; Mikropoulos \& Natsis, 2011).

In our distance training environment, a Community of Practice (CoP) was created. A CoP as a constant, robust social network of participants who produce, develop and share an overlapping knowledge, beliefs, values, history, and experiences based on a common practice and-or reciprocal enterprise (Wenger, McDermott \& Snyder, 2002; Barbera, 2004; Kaufman, Kelly \& Ireland, 2008). CoP is a multidimensional concept, where instructors promote the learning focus instead of the teaching focus, being a notable strategy for e-learning practitioners to expand their range of skills. Two key purposes can be served by an online CoP: (a) delineate a place for instructors' interactions; and (b) delineate a place for students' interactions either with other students or with the trainer, and team working (Wenger et al., 2002; Kaufman et al., 2008).

\subsection{Purpose of the Research}

According to Leonard, Kalinowski \& Andrews (2014), teaching and understanding of certain biological processes and principles are not simple and the reasons why this happens are not clear because of the complexity of students' ideas and the scientific findings. The main question remains: what can teachers do to help their students to reshape their preexisting perceptions of biological phenomena towards to more scientific approach? To answer this question, the researchers resulted to five fields that required further investigation including the support and training of teachers' teaching biology. In particular, the purposes of our study are (a) the description of the design and evaluation of a training program based on the model of Pedagogical Content Knowledge (PCK), and (b) the initial assessment of the main results of the program to a limited number of secondary education Greek science teachers.

\subsection{Content - Seminar Duration}

The training course lasted for 6-weeks. It has been conducted during school period 2014-2015, and its content was defined according to the results of the analysis of questionnaires (Stasinakis \& Athanasiou, 2016) and interviews (Stasinakis \& Athanasiou, 2012), as well as the demand for a training course in specialized PCK of the "Teaching of Evolution (ToE)". It was entitled: "Evolving the Teaching of Evolution by selecting Good Teaching Practices". Figure 1 shows the home page of the course in the Moodle platform.

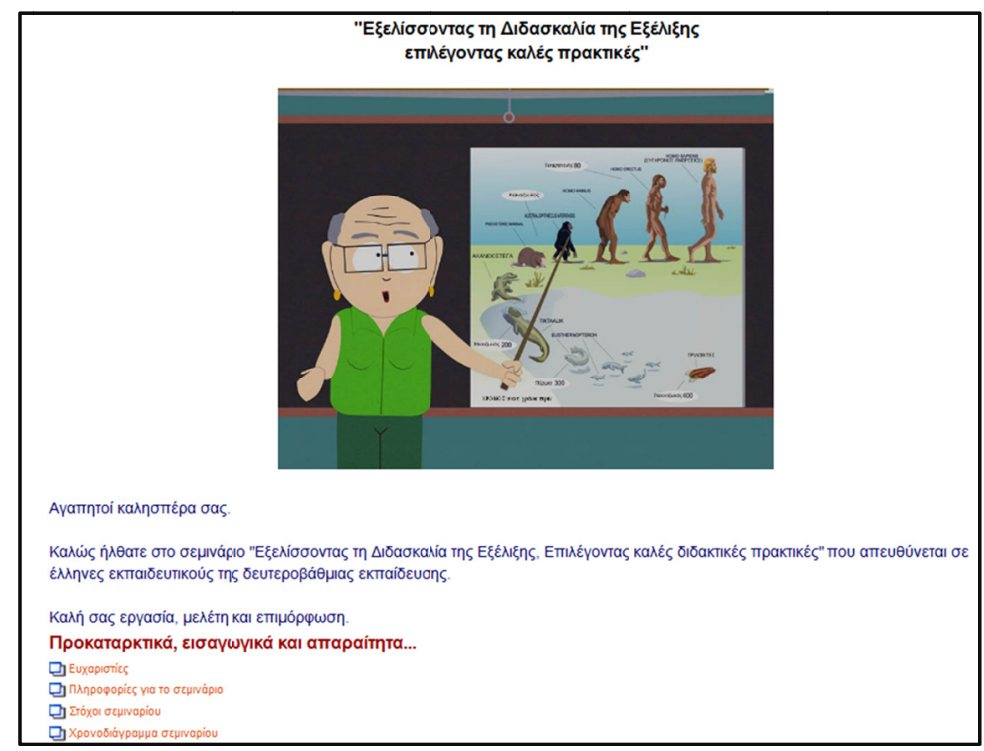

Figure 1. Screenshot of the Training Seminar

Each week the participants had to implement a series of activities: to study some material related to the thematic of the week, to attend an educational meeting, to submit assignments, to record remarks, concerns and ideas about the 
thematic of the week. The synchronous platform was used only for online lectures, where the participants who attended the speaker could put in using several functionalities of the platform. We used the asynchronous platform for study material, activities, comments, discussions, assessments, assignments, etc.

For each week the objectives and the prerequisites of prior week's material, were defined. Participants were called to submit questions-comments that they would like to be discussed by the speaker, we presented them in detail the activities that should be completed, including their deliverables. In the last two weeks of the training course, participants presented their own activities - teaching practices related to ToE.

In the seminar's "Introduction" we addressed issues related to the basic principles of the training seminar and the technical aspects of the e-learning platforms. The introduction module had been:

- Preliminary notes, introductory remarks. In this section the objectives of the seminar were presented, the timetable, the organizational information about the seminar and a "thank-you-message" to the participants.

- The first instructions. Describe basic operating rules in the asynchronous platform, such as communication issues, material's study as a prerequisite for the following sections, communication and text writing rules, computers' technical requirements for participation in synchronous (web-conference) meetings, primary activities within the platform (in order for participants to familiarize with its use, such as sending emails, updating their profiles, participation in discussions, etc.) are described.

- Introductory discussions. Participation in forums, where they answered primary issues, such as objectives from their participation in the seminar or ways of using the instructions by official bodies regarding the ToE.

- Technical issues - Questions. Detailed issues related to technical requirements and uses. A forum had been created, where participants could record any technical question-problem, in order to be provided by direct instructions.

In details, the thematic of seminar were:

- $\quad 1^{\text {st }}$ week: "International Bibliography - Data from Greek case studies". Literature data regarding the ToE was presented; presentation - familiarization with Moodle (asynchronous) and Elluminate (synchronous) platforms. Participants should complete two activities which recorded their teaching practices (by creating a lesson plan about ET and NS) and their views about ET (by commenting a text which describes opinions of teachers about $\mathrm{ET})$.

- $\quad 2^{\text {nd }}$ week: "Scientific issues concerning the ET and NS". Discussion upon scientific and epistemological issues regarding ET, synchronous lecture with a scientist expertized in ET. Two activities aiming at motivating them to record common scientific errors that teachers make during the ToE by a role play activity (they supposed to participate in a public discussion about ET, answering questions) and to notice the scientific errors that presented in Greek textbooks.

- $3^{\text {rd }}$ week: "Teaching issues concerning the ET and NS". Material of the specified didactics for ToE had been presented, a synchronous lecture from a scientist expertized in ToE. Participants should complete two activities on teaching issues: to record their ability to identify common misconceptions about ET and NS among their students and to construct a concept map about an issue of ET.

- $4^{\text {th }}$ week: "Synthesis of Science, Teaching \& School Context: Pedagogical Content Knowledge - PCK". Description and analysis of the PCK model, adjustment of its general principles to the Greek status quo, while during lecture of the week the importance of PCK for ToE was highlighted and a participant presented his/her options about ToE issues. Participants had to complete two activities regarding teaching practice and PCK (create a lesson plan using the Greek curriculum and its notes; study of PCK components and provide ideas about more components that should be part of this model).

- $5^{\text {th }}$ week: "Lesson Plan, Curriculum Planning, Teaching Implementations". Discussion and presentation of a lesson plan, while in the lectures of the week participants presented various didactic proposals concerning the ToE. Participants had to complete an activity creating a lesson plan regarding the ToE, based on all subjects they had learned during the seminar.

- $6^{\text {th }}$ week: "Seminar Completion, Teaching Practices, Evaluation". Seminar evaluation; further material that could assist the participants in the better planning of their teaching interventions, while in the lectures of the week participants presented various didactic proposals concerning the ToE. Submission of evaluation questionnaires. 


\section{Methodology}

The term evaluation refers to the process of value determination of an object (Scriven, 1991). When the 'object' to be valued is a training program, the assessment process cannot be based on an arbitrary, spontaneous or intuitive opinion or judgment, but involve the systematic collection of information on the characteristics, activities and program results. This research was based on Stufflebeam evaluation model (2003), better known by the acronym CIPP (Context-Input-Process-Product). The CIPP is oriented to evaluate educational programs, focused mainly on improving and proper functioning of the actions during the program and less in evidence and accountability. Specifically, the evaluation mechanism developed in our study, included the use of the following elements:

(a) research needs of participants,

(b) review of our previous study,

(c) discourse analysis of participants' deliverables,

(d) analysis of written evidence and

(e) bibliographic research.

\subsection{E-learning Platforms}

For the training course used synchronous and asynchronous e-learning platforms. The selection criteria of the platforms were the following ones:

- to provide free and easy access for all participants,

- to have the minimum requirements in technological equipment, so that all participants are able to attend these sessions seamlessly,

- to have the option to keep the material of the training seminar, so that participants are able to refer to it whenever they wish,

- to have ease in the use by those who are not familiar with computers in order to exclude any quitting due to of technical weakness of the participants,

- to enable the participants to interfere with the educational process anytime, either by expressing their concerns or by actively intervening and changing the processes of the training seminar.

\subsubsection{Asynchronous and Synchronous E-Learning Platforms}

For the asynchronous e-learning, Moodle (version 1.9.9+) was used. The platform had been installed on a private server, so that we could have full control on organizational, functional and administrative issues (Stasinakis \& Kalogiannakis, 2015).

For the synchronous e-learning, Elluminate was used. We used this free of charge. During the free use of the service, certain requirements had been necessitated, such as:

- free access,

- recording of the presentation on a video and storage at the servers of the group,

- pre-registration and availability check for the virtual room (vRoom) where the meetings were held,

- two hours' maximum duration of each meeting.

The above conditions did not affect our meetings, so we accepted them and we were able to use free of charge an excellent easy to use e-learning platform. Thus, we organized one online meeting per week in a virtual videoconference room (vRoom), to implement our teleconference (Web Conference or Webinar).

\subsection{Participants}

Upon completion of the submission of the questionnaires (Stasinakis \& Athanasiou, 2016), the participants were asked to express their interest in participating in the training course. In total, 64 people expressed an interest to participate. When the seminar was to be started, an invitation for confirmation of their participation was sent again. The new call included all the seminar details: duration, time schedule, activities. Out of the initial 64, 32 finally replied positively. Consequently, they were instructed to register within the platform Moodle and 27 finally did. Registration instructions for the seminar entitled "Evolving the Teaching of Evolution by selecting Best Teaching Practices" was the next step and 23 registered. Out of them, 16 fully attended the seminar and participated in all activities and obligations, who were granted by a certificate of attendance. 


\subsection{Questionnaire's Answers}

The seminar had been evaluated by two questionnaires. One referring to the evolution seminar (15 out of 16 participants answered) and another (COLLES actual) referring to the distance training (14 out of 16 participants answered). As it is mentioned in Moodle's documentation, "COLLES comprises an economical 24 statements grouped into six scales, about the quality of the on-line learning environment: Relevance (How relevant is on-line learning to trainees' professional practices?), Reflective Thinking (Does on-line learning stimulate trainees' critical reflective thinking?), Interactivity (To what extent do trainees engage on-line in rich educative dialogue?) Tutor Support (How well do tutors enable trainees to participate in on-line learning?), Peer Support (Is sensitive and encouraging support provided on-line by fellow trainees?), Interpretation (Do trainees and tutors make good sense of each other's on-line communications?). The COLLES provides information about the interactive capacity of the web, for engaging trainees in dynamic learning practices".

\section{Results about Evolution Seminar}

\subsection{Characteristics of the Sample}

\subsubsection{Education Level}

All the participants taught in secondary education. Approximately half (53.3\%) taught in both lower (Gymnasium) and upper (Lyceum) High School, while the rest taught mainly in lyceum (33.3\%) and secondarily in gymnasium (13.3\%). It was important to have representatives from all educational levels, as they address different cognitive students' skills and, therefore, they should improve different components of their individual PCK.

\subsubsection{Professional Experience}

One of the most important components of the PCK is the teaching experience, and mainly the ability of teachers to use focused teaching practices that have been developed during their long-term presence in the classroom. Teachers with less teaching experience have the opportunity to improve their individual PCK. In our sample, approximately half of them (53.4\%) had short educational experience (up to 10 years), and if we add $20 \%$ of the participants with a teaching experience of 11-15 years, we conclude that our sample generally consisted of teachers with less experience. Only $13.3 \%$ of the participants were teachers for more than 25 years. From our personal contact during the seminar and the completion of their activities, we found that they were not inadequate in scientific issues of ET but mainly on issues regarding teaching and daily practice in the class. According to the principles of the PCK this is expected, as the experience comprises an important component for the teacher to improve his/her teaching practice in the class.

\subsubsection{Bachelor Degree}

The participants were mainly Biologists (80\%), Agronomist (6.7\%) and Physicists (13.3\%). As the invitation for participation was open and addressed to all those who had completed and submitted the questionnaire, the limited participation of other disciplines may be due to a less interest on the subject matter of the course or even in their sense of being a recondite subject. The limited participation, does not create any problem in our research, since our goal was not to compare the effectiveness of PCK among different disciplines, but to ascertain if a training program about ToE that has been organized on the principles of PCK will be interesting for the participants and they shall record some improvement of their individual PCK.

\subsubsection{Previous Experience with Moodle Platform}

A slight percentage of the participants had previous experience of the e-learning platform Moodle $(40 \%$ versus $60 \%$ with no experience). As it turned out during the seminar, this was not a problem, as both the organization of the seminar and the usability of the platform did not bring about any difficulty to the participants. Distinctive and clear instructions, continuous communication with the tutors and immediate feedback, helped them familiarize quite fast with the use of the e-learning platform.

\subsection{Questionnaire about the Evolution Seminar}

\subsubsection{Course's Components}

Participants had to evaluate the components of the course using a Likert (1-5) rating scale. 


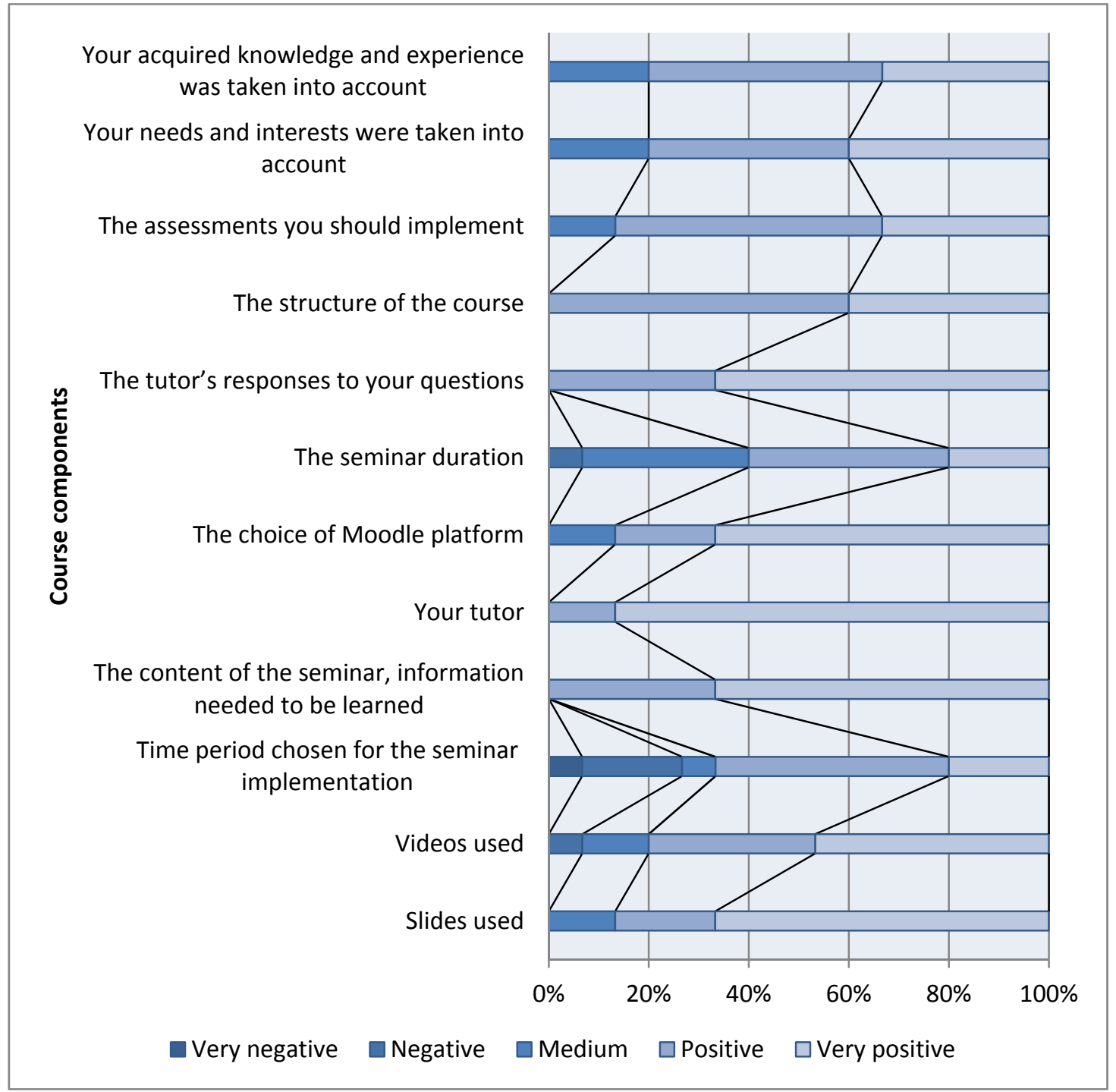

Figure 2. Evaluation of Course Components

Table 1. Evaluation of Course Components*

\begin{tabular}{lcccccc}
\hline Course components & $\mathbf{1}$ & $\mathbf{2}$ & $\mathbf{3}$ & $\mathbf{4}$ & $\mathbf{5}$ & Mean \\
\hline Slides used & 0 & 0 & 13.3 & 20 & 66.7 & 4.5 \\
Videos used & 0 & 6.7 & 13.3 & 33.3 & 46.7 & 4.2 \\
Time period chosen for the seminar implementation & 6.7 & 20 & 6.7 & 46.7 & 20 & 3.5 \\
The content of the seminar, information needed to be learned & 0 & 0 & 0 & 33.3 & 66.7 & 4.7 \\
Your tutor & 0 & 0 & 0 & 13.3 & 86.7 & 4.9 \\
The choice of Moodle platform & 0 & 0 & 13.3 & 20 & 66.7 & 4.5 \\
The seminar duration & 0 & 6.7 & 33.3 & 40 & 20 & 3.7 \\
The tutor's responses to your questions & 0 & 0 & 0 & 33.3 & 66.7 & 4.7 \\
The structure of the course & 0 & 0 & 0 & 60 & 40 & 4.4 \\
The assessments you should implement & 0 & 0 & 13.3 & 53.3 & 33.3 & 4.2 \\
Your needs and interests were taken into account & 0 & 0 & 20 & 40 & 40 & 4.2 \\
Your acquired knowledge and experience was taken into account & 0 & 0 & 20 & 46.7 & 33.3 & 4.13 \\
\hline
\end{tabular}

*: $1=$ Very negative, $2=$ Negative, $3=$ Medium, $4=$ Positive, $5=$ Very positive, percentage $\%$ and mean 
We found that the participants evaluated positive the various components of the material and the organization of the seminar, as it ranges in mean> 4.0 (in the scale of "Positive" - "Very Positive"). Only in the time issue (period of implementation, duration) there is a general trend towards the "Medium" scale: it was difficult for participants to attend the seminar due to their daily obligations at school and due to the volume of matter addressed.

They proposed the duration of the course to be extended and to be organized in a period that they will have less liabilities at their school. Maybe elongating the seminar could increase their daily participation, since they would have to carry out less activities and studying less material per week.

\subsubsection{General Perception about Training Courses}

Participants had to evaluate their general perception on training courses.

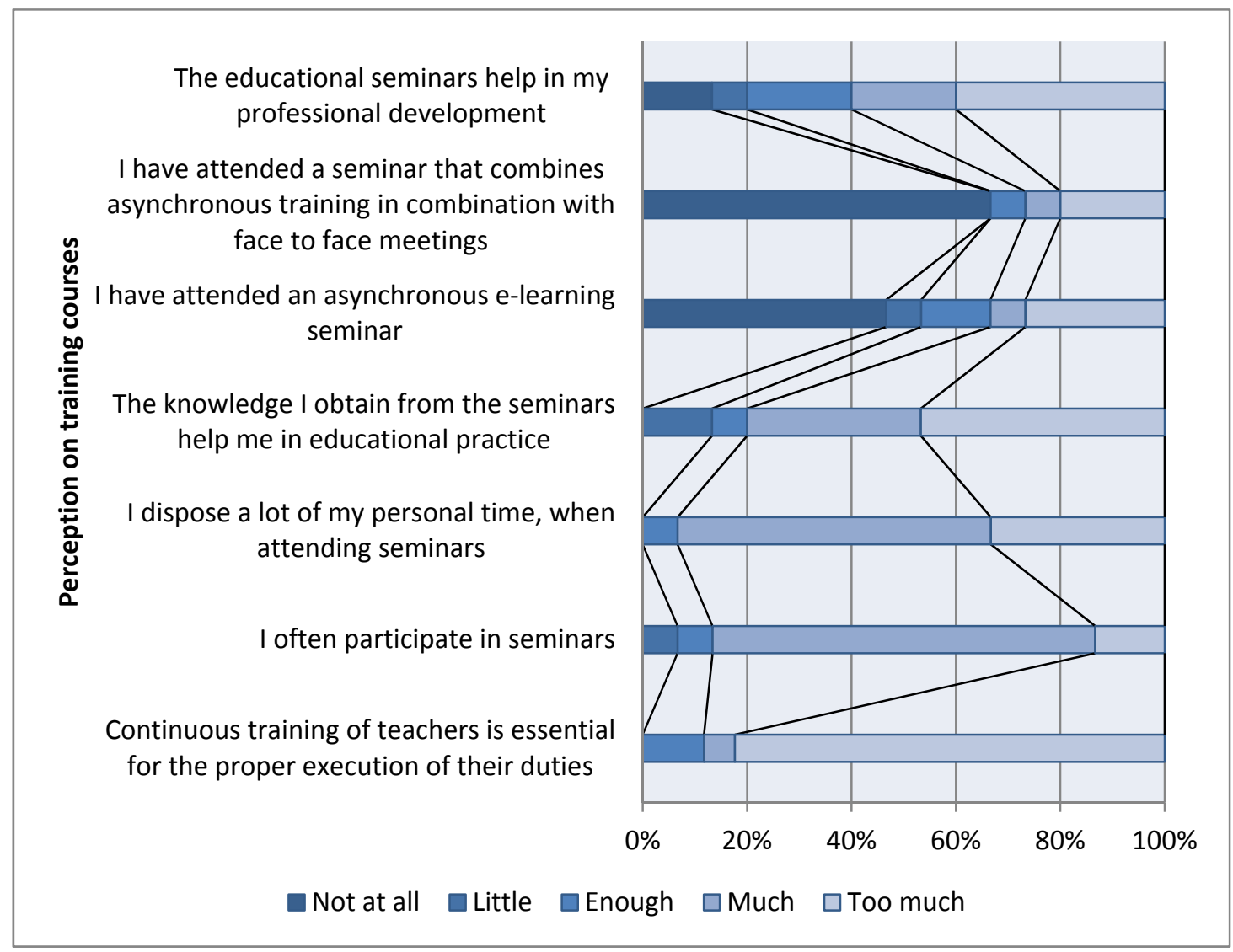

Figure 3. Evaluation of Perceptions about Training Courses

Table 2. Evaluation of Perceptions about Training Courses*

\begin{tabular}{|c|c|c|c|c|c|c|}
\hline Perceptions about training courses & 1 & 2 & 3 & 4 & 5 & Mean \\
\hline $\begin{array}{l}\text { Continuous training of teachers is essential for the proper } \\
\text { execution of their duties }\end{array}$ & 0 & 0 & 0 & 6.7 & 93.3 & 4.9 \\
\hline I often participate in seminars & 0 & 6.7 & 6.7 & 73.3 & 13.3 & 3.9 \\
\hline I dispose a lot of my personal time, when attending seminars & 0 & 0 & 6.7 & 60 & 33.3 & 4.3 \\
\hline $\begin{array}{l}\text { The knowledge I obtain from the seminars help me in } \\
\text { educational practice }\end{array}$ & 0 & 13.3 & 6.7 & 33.3 & 46.7 & 4.1 \\
\hline I have attended an asynchronous e-learning seminar & 46.7 & 6.7 & 13.3 & 6.7 & 26.7 & 2.6 \\
\hline $\begin{array}{l}\text { I have attended a seminar that combines asynchronous training } \\
\text { in combination with face to face meetings }\end{array}$ & 66.7 & 0 & 6.7 & 6.7 & 20 & 2.1 \\
\hline The educational seminars help in my professional development & 13.3 & 6.7 & 20 & 20 & 40 & 3.7 \\
\hline
\end{tabular}

*: $1=$ Not at all, $2=$ Little, $3=$ Enough, $4=$ Much, $5=$ Too much, percentage $\%$ and mean 
It is striking that almost all participants (93.3\%) associate lifelong learning with better performance in their profession. They do not connect lifelong learning with their professional development (only $40 \%$ considers that seminars helping "Too much" their professional development). Interestingly, most of them (80\%) think that seminars help their teaching practice $(46.7 \%+33.3 \%)$. We noted that the mean for participating in such e-learning seminars is low (<3.0, scale "Enough"), a few have attended organized seminars in this way.

\subsubsection{Participants' Objectives and Expectations Fulfilment by the Seminar Implementation}

All the participants $(100 \%)$ noted that the objectives and expectations of participation in the seminar were fully fulfilled. This is another indication that the seminar's organization and implementation in the framework of PCK had a positive impact on the participants and improved their individual PCK by involving them in practical issues related to the ToE. For the future, a research question could be whether these teachers, who were trained with a program based on the principles of the PCK, can achieve better performance in their classes to the ones who attend other seminars or do not attend seminars.

\subsubsection{Evaluate Feelings You Experienced During Your Participation in the Seminar}

Participants had to evaluate the feelings they experienced during the seminar.

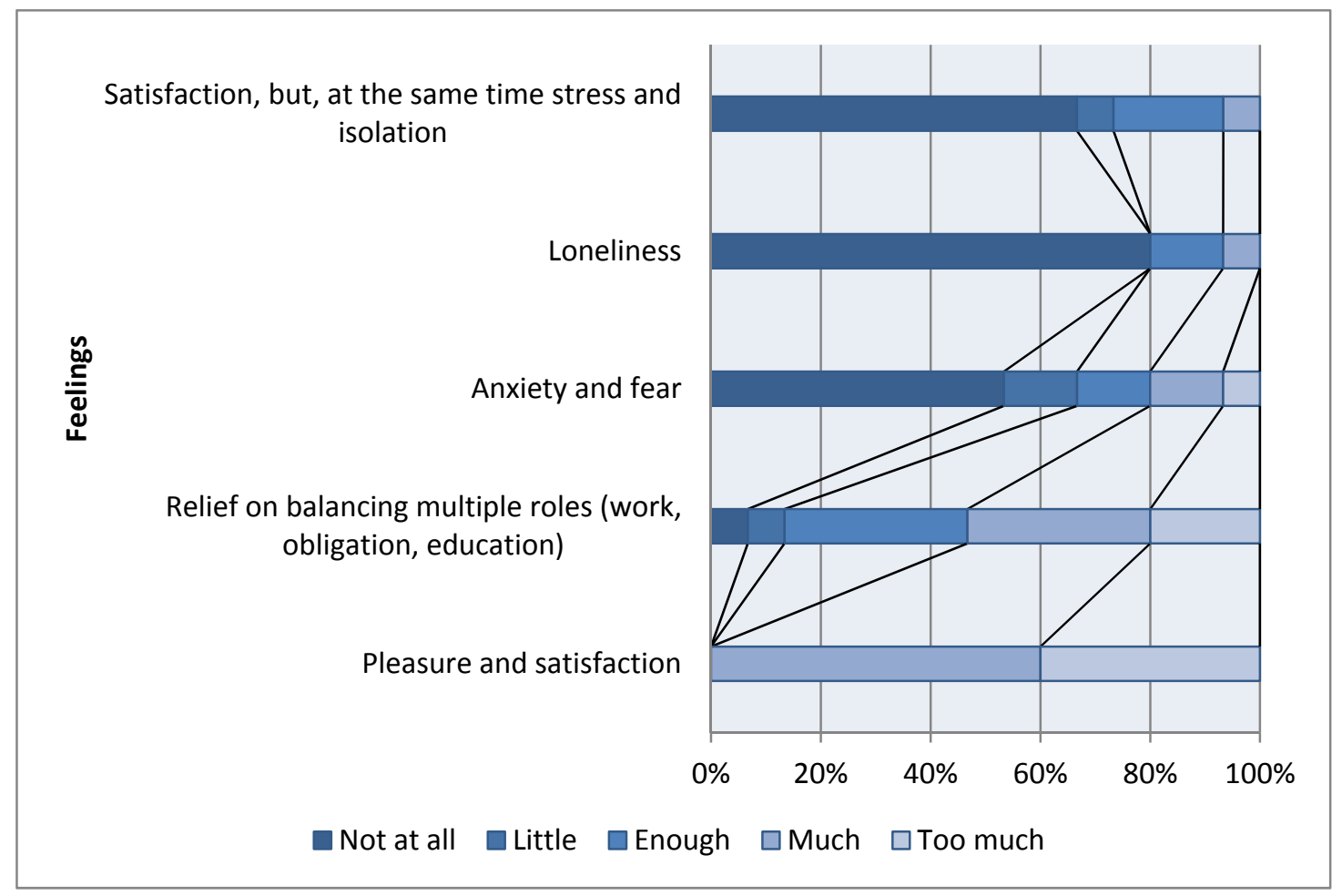

Figure 4. Evaluation of Their Feelings

Table 3. Evaluation of Their Feelings

\begin{tabular}{lcccccc}
\hline Teachers' feeling about the course & $\mathbf{1}$ & $\mathbf{2}$ & $\mathbf{3}$ & $\mathbf{4}$ & $\mathbf{5}$ & Mean \\
\hline Pleasure and satisfaction & 0 & 0 & 0 & 60 & 40 & 4.4 \\
Relief on balancing multiple roles (work, training, daily occupations) & 6.7 & 6.7 & 33.3 & 33.3 & 20 & 3.5 \\
Anxiety and fear & 53.3 & 13.3 & 13.3 & 13.3 & 6.7 & 2.1 \\
Loneliness & 80 & 0 & 13.3 & 6.7 & 0 & 1.5 \\
Satisfaction, but, at the same time stress and isolation & 66.7 & 6.7 & 20 & 6.7 & 0 & 1.7 \\
\hline
\end{tabular}

*: $1=$ Not at all, 2=Little, 3=Enough, 4=Much, 5=Too much, percentage $\%$ and mean 
We generally found that negative feelings, such as anxiety and fear or loneliness low scores are observed (mean 2.1 and 1.5 respectively) and high scores in positive feelings, such as pleasure and satisfaction (mean 4.4). We would expect higher performance in statement "Relief on balancing multiple roles (work, training, daily occupations)" (mean 3.5), since one of the advantages of distance learning is that it allows participants to organize it in their own time. The poor performance could be explained by the finding at a previous point in the questionnaire that the course duration was short and its implementation time was inappropriate, as the participants had several obligations with their daily work in their school.

\subsubsection{E-learning Principles}

Participants had to evaluate the statements below, about the principles of distance education when designing the training seminar that we were taken into account.

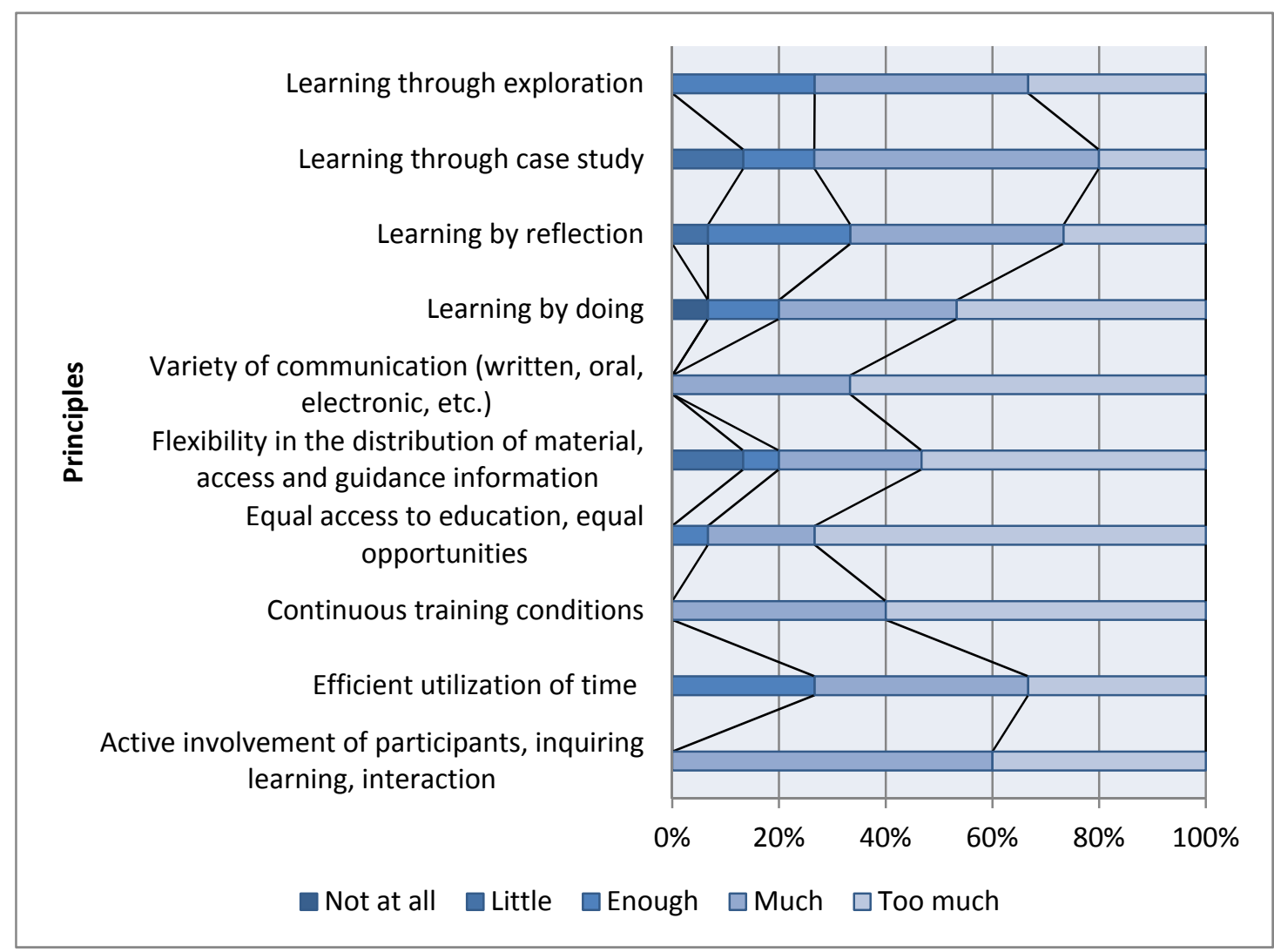

Figure 5. Statements of E-Learning Principles That Were Taken Into Account

Table 4. Evaluation of the Statements of E-Learning Principles That Were Taken Into Account

\begin{tabular}{lcccccc}
\hline Statements of e-learning principles & $\mathbf{1}$ & $\mathbf{2}$ & $\mathbf{3}$ & $\mathbf{4}$ & $\mathbf{5}$ & Mean \\
\hline $\begin{array}{l}\text { Active involvement of participants, inquiring learning, } \\
\text { interaction }\end{array}$ & 0 & 0 & 0 & 60 & 40 & 4.4 \\
Efficient utilization of time & 0 & 0 & 26.7 & 40 & 33.3 & 4.1 \\
Continuous training conditions & 0 & 0 & 0 & 40 & 60 & 4.6 \\
$\begin{array}{l}\text { Equal access to education, equal opportunities } \\
\text { Flexibility in the distribution of material, access and } \\
\text { guidance information }\end{array}$ & 0 & 0 & 6.7 & 20 & 73.3 & 4.7 \\
Variety of communication (written, oral, electronic, etc.) & 0 & 0 & 0 & 33.3 & 66.7 & 4.7 \\
Learning by doing & 6.7 & 0 & 13.3 & 33.3 & 46.7 & 4.1 \\
Learning by reflection & 0 & 6.7 & 26.7 & 40 & 26.7 & 3.9 \\
Learning through case study & 0 & 13.3 & 13.3 & 53.3 & 20 & 3.8 \\
Learning through exploration & 0 & 0 & 26.7 & 40 & 33.3 & 4.1 \\
\hline$* .1-N o t a t$
\end{tabular}

*: $1=$ Not at all, 2=Little, 3=Enough, 4=Much, 5=Too much, percentage $\%$ and mean 
We found that for most statements participants" answers ranged in the "Much" - "Too much" scale. We noted that in eight of the ten indicators - characteristics of distance education, participants scored mean $>4.0$ (i.e. ranging in scale "Much" and "Too Much"). Two characteristics ("Learning by reflection" and "Learning through case study") scored mean $<4.0$ (3.9 and 3.8 respectively). The relatively poor performance in these two indicators, as we will also see in COLLES research, is mainly due to the fact that participants did not interact with each other in a high level.

There is much room for improvement at this point, although we made efforts towards this direction. We estimate that the pressure of the time and the length of content played partially a deterrent role on any possibility of interaction. However, in the framework of the seminar, participants were encouraged to interact: by posting their opinions and participating in forum debates, by presenting their personal work on the synchronous e-learning platform, by discussing common issues that arose in the activities and study, etc.

\subsubsection{Components of PCK}

Participants had to evaluate the components of their individual PCK that had been improved with the completion of the training seminar.

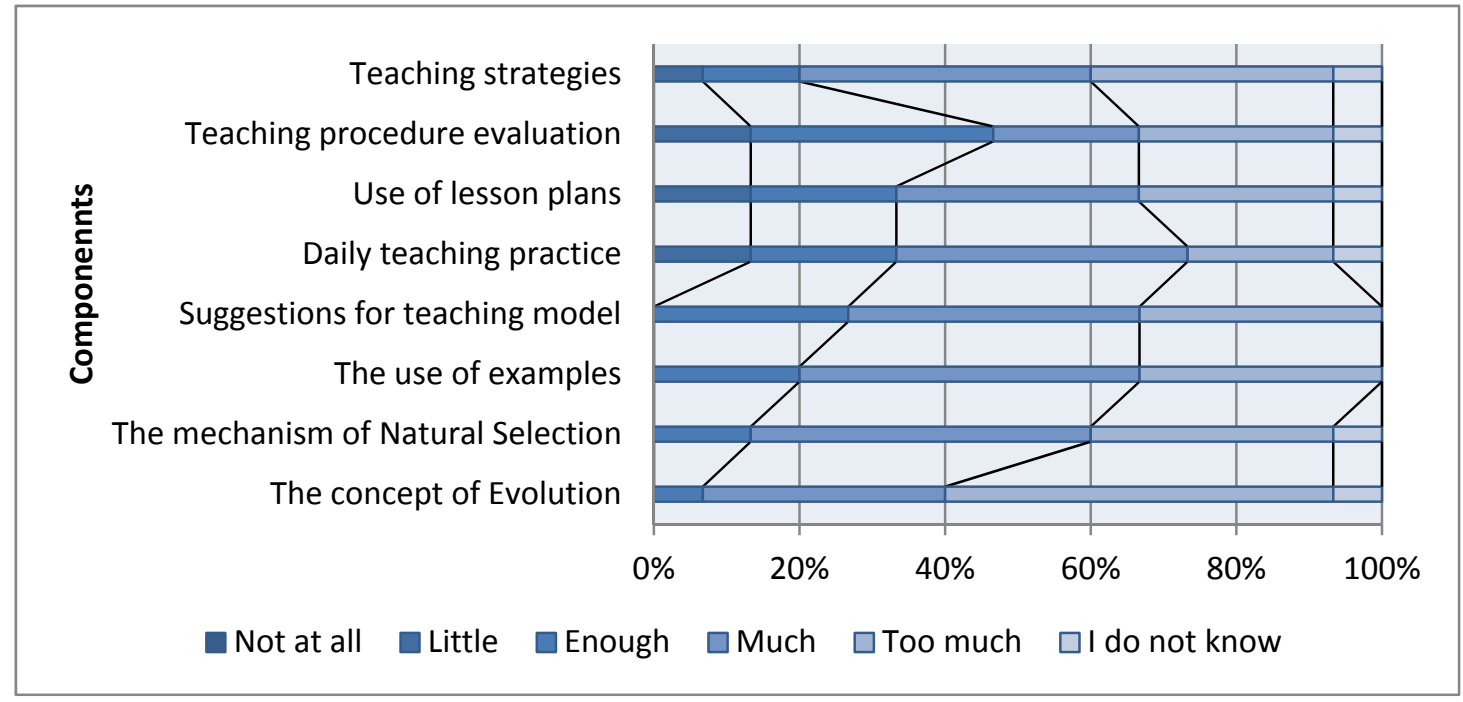

Figure 6. Components of Individual PCK That Have Been Improved

Table 5. Components of Individual PCK that Have been Improved**

\begin{tabular}{lcccccc}
\hline Components of individual PCK & $\mathbf{1}$ & $\mathbf{2}$ & $\mathbf{3}$ & $\mathbf{4}$ & $\mathbf{5}$ & Mean \\
\hline The concept of Evolution * & 0 & 0 & 6.7 & 33.3 & 53.3 & 4.6 \\
The mechanism of Natural Selection * & 0 & 0 & 13.3 & 46.7 & 33.3 & 4.3 \\
The use of examples & 0 & 0 & 20 & 46.7 & 33.3 & 4.1 \\
Suggestions for teaching model & 0 & 0 & 26.7 & 40 & 33.3 & 4.1 \\
Daily teaching practice * & 0 & 13.3 & 20 & 40 & 20 & 3.9 \\
Use of lesson plans * & 0 & 13.3 & 20 & 33.3 & 26.7 & 3.9 \\
Teaching procedure evaluation * & 0 & 13.3 & 33.3 & 20 & 26.7 & 3.8 \\
Teaching strategies * & 0 & 6.7 & 13.3 & 40 & 33.3 & 4.2 \\
\hline
\end{tabular}

*: $1=$ Not at all, $2=$ Little, $3=$ Enough, $4=$ Much, $5=$ Too much, percentage $\%$ and mean

**: in any component $6.7 \%$ answered "I do not know"

We found that in the most components of PCK participants perform positively (mean $>4.0$ or very close to 4.0 ). 


\subsubsection{Comments Regarding Seminar Improvement}

The participants commented on the seminar and made suggestions. We quote some of them:

- "I would prefer it in a less busy period, during June or July, lasted more and face-to-face meetings to be made".

- "Should be less pressure for the activities, trainer asses them and participants to be able to re-submit them with the required corrections".

- " "We should have had more time available after webinars, in order to be able to exchange views".

- “Our colleagues' proposals on the ToE were very constructive. Moreover, instructions from the tutor and his references to various resources were fully informative".

- "Longer duration and slower pace of attendance".

- "I would prefer more participants to talk about my activities, because I am not able to discuss all of my ideas. If the discussion took place in a wider audience, maybe several of my thoughts had been evolved".

Furthermore, they said, according to their initial expectations, that the training seminar helped them:

- "With my training regarding the ToE, with teaching practices, with designing lesson plans, with the contact with colleagues, with scientific knowledge I realized some of my weaknesses in scientific and teaching options for the subject".

- "Interesting literature, clarification of issues related to the ToE, interesting lectures specialists, teaching practices and recommendations".

- "Knowledge systematization regarding evolution and its theories, review of erroneous beliefs and teaching practices, reflection, exchange of views and experience with colleagues, understanding of the 'Pedagogical Content Knowledge' concept".

- "To the better understanding and clarification of some concepts of ET and Nature of Science (NoS), and to the new teaching techniques that I could apply on ToE".

- ' "It helped me to trace more easily the students' misconceptions on basic concepts of evolution, rather my own faults. I feel more confident both in subject and in its way of teaching (I feel now that I can clarify more efficiently some key-points in evolutionary processes)".

- "To teach the subject of biology in lower high school through the unifying theory of evolution".

- "To the better understanding of concepts, material and information about teaching methods, new arguments on ToE, knowledge broadening, correction of erroneous concepts on the issues of ET".

- "In giving me more ideas on how I can teach the ET in class".

- "Improvement of PCK components, improvement of the daily teaching practice, development of teaching strategies, familiarization with the modern evaluation methods of the teaching process".

- "I got ideas on the ToE, I got excellent comments on my lesson plans, I clarified scientific points that were unclear to me, I discovered the Moodle platform, I discovered the electronic conference, I had substantial corrections (and subtle) of my technical weaknesses".

- "It verified some of my teaching ideas and particularly the value of their application in education. I gained a lot of information for my deficiencies. All these, even if we don't realize it, could be transferred into our classes".

- "Seminar was an opportunity to enrich our thinking and our teaching".

- “Utilization in ToE, practice with Moodle and ideas about using it in education".

- "Very useful interaction with fellow teachers and academics on the issue of evolution".

4.3 Questionnaire about Using E-Learning Platform, COLLES Research

Initially we present an overall diagram with all scales of COLLES research. 


\section{Summary}

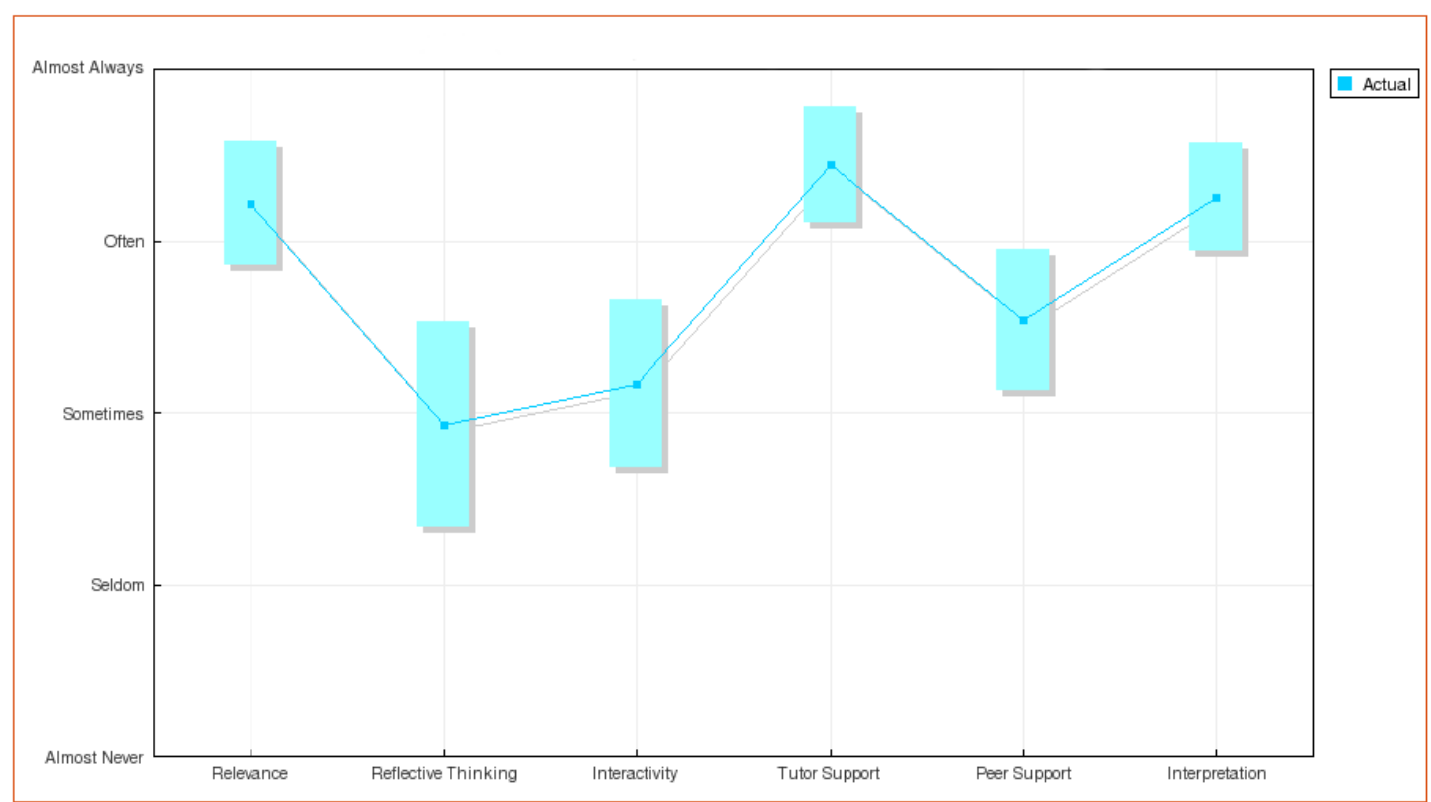

Figure 7. Summary of COLLES Research

We detect very good performance at the scales "Relevance", "Tutor Support", "Interpretation", a relatively good performance at the scale "Peer Support" and moderate performance at the scales "Reflective Thinking" and "Interactivity". The best score appears to be at the scale "Tutor Support", while the lowest at the scale "Reflective Thinking".

For each of the scales of COLLES research, the relevant charts are shown:

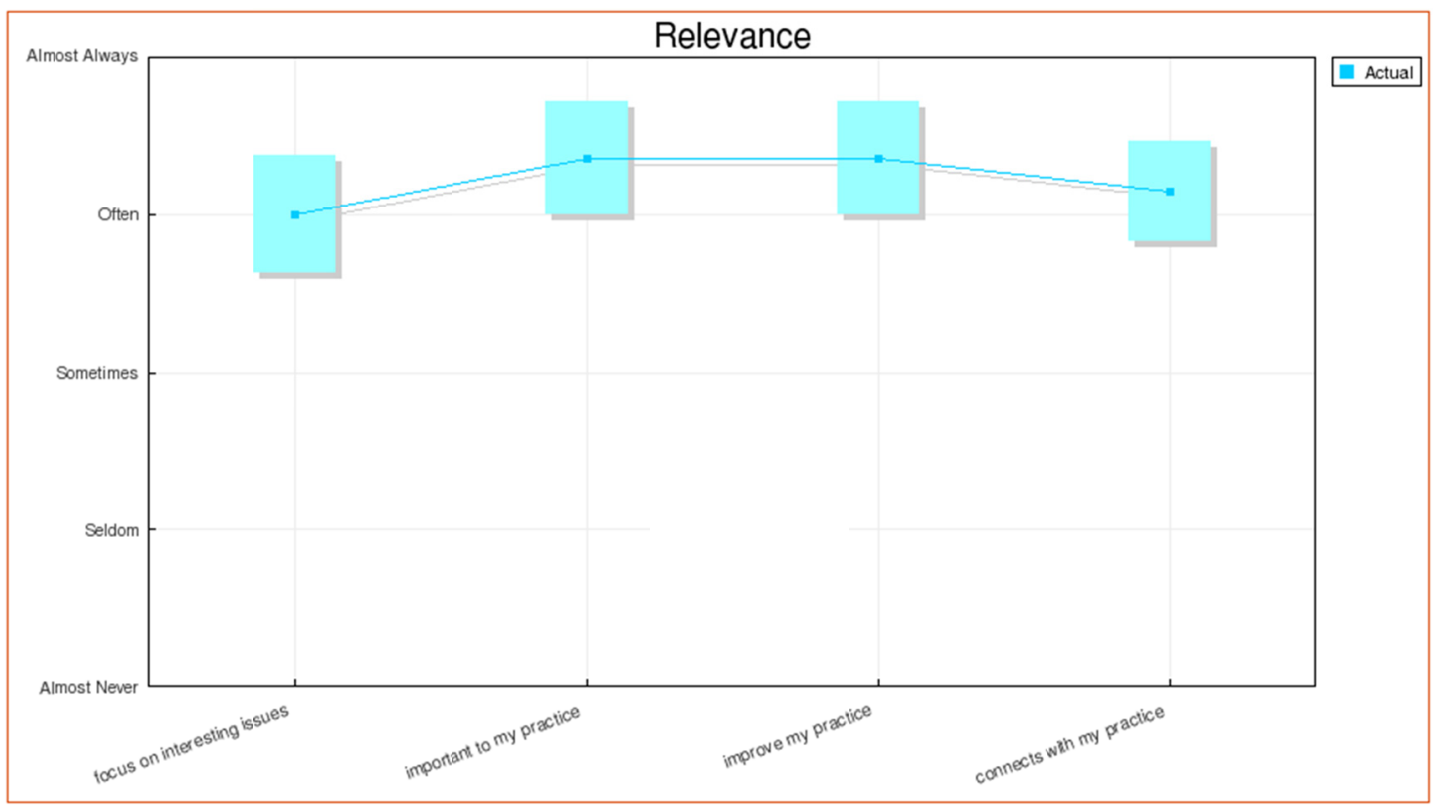

Figure 8. The Scale "Relevance" of COLLES Research

We conclude that the e-learning platform has been able to help all the participants in practical issues, since all the statements had high performance. 


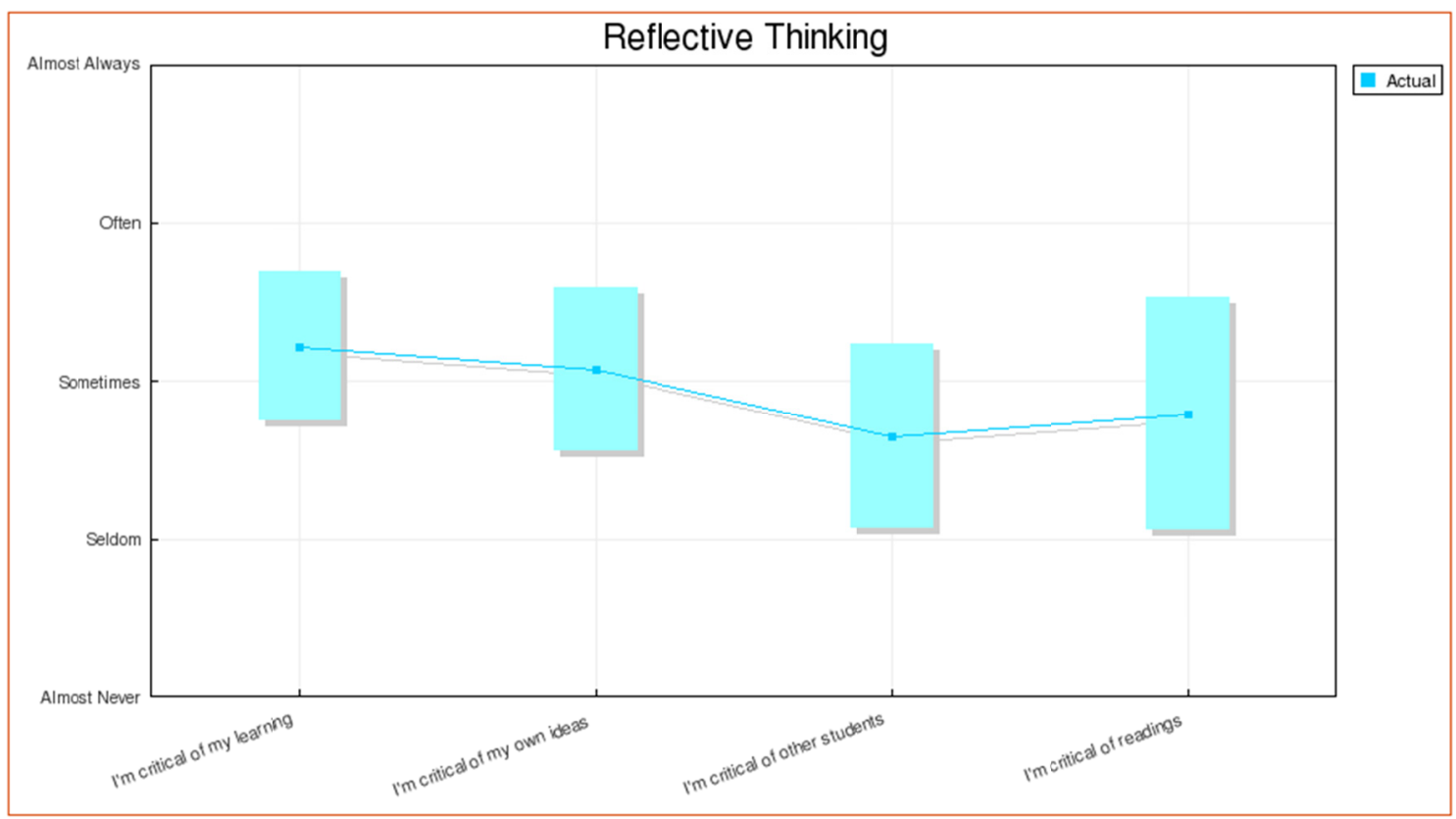

Figure 9. The scale "Reflective Thinking" of COLLES research

We conclude poor performance in all statements, therefore the seminar did not manage to activate their critical thinking.

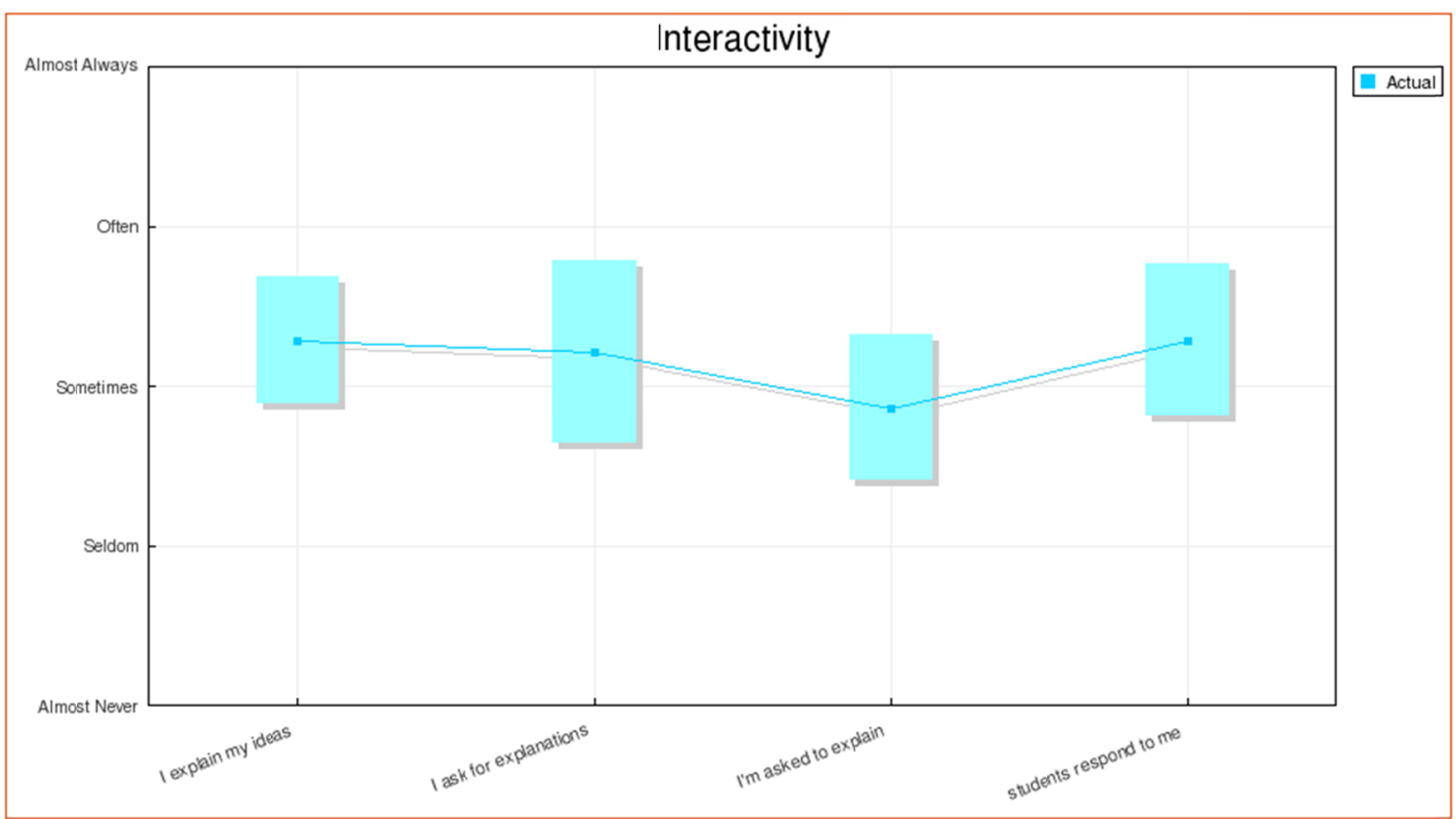

Figure 10. The Scale "Interactivity" of COLLES Research

We conclude poor performance, as we did not manage to activate cooperation among the participants. 


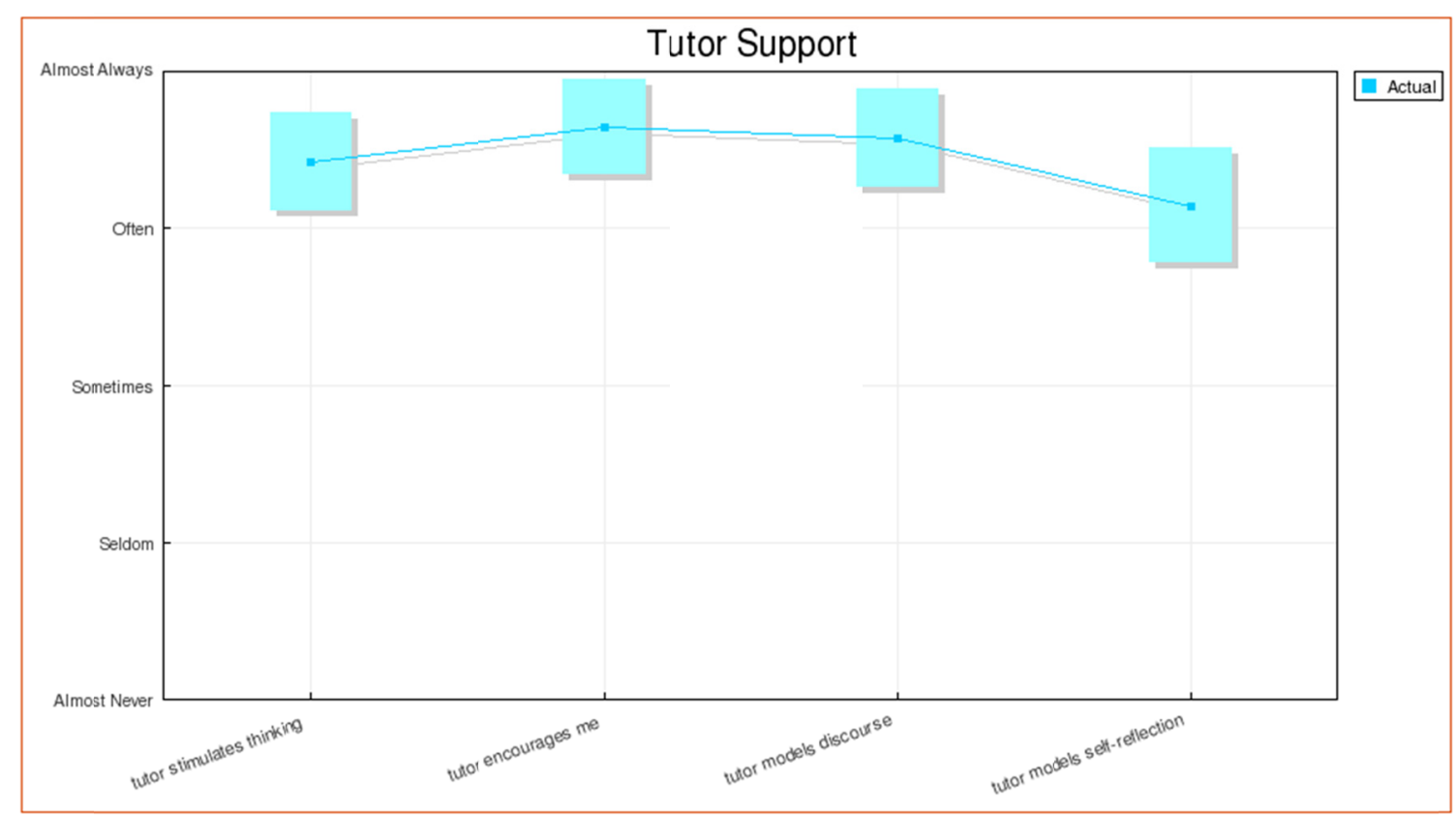

Figure 11. The Scale "Tutor Support” of COLLES Research

We conclude high performance, mainly in encouragement and involvement in discussions.

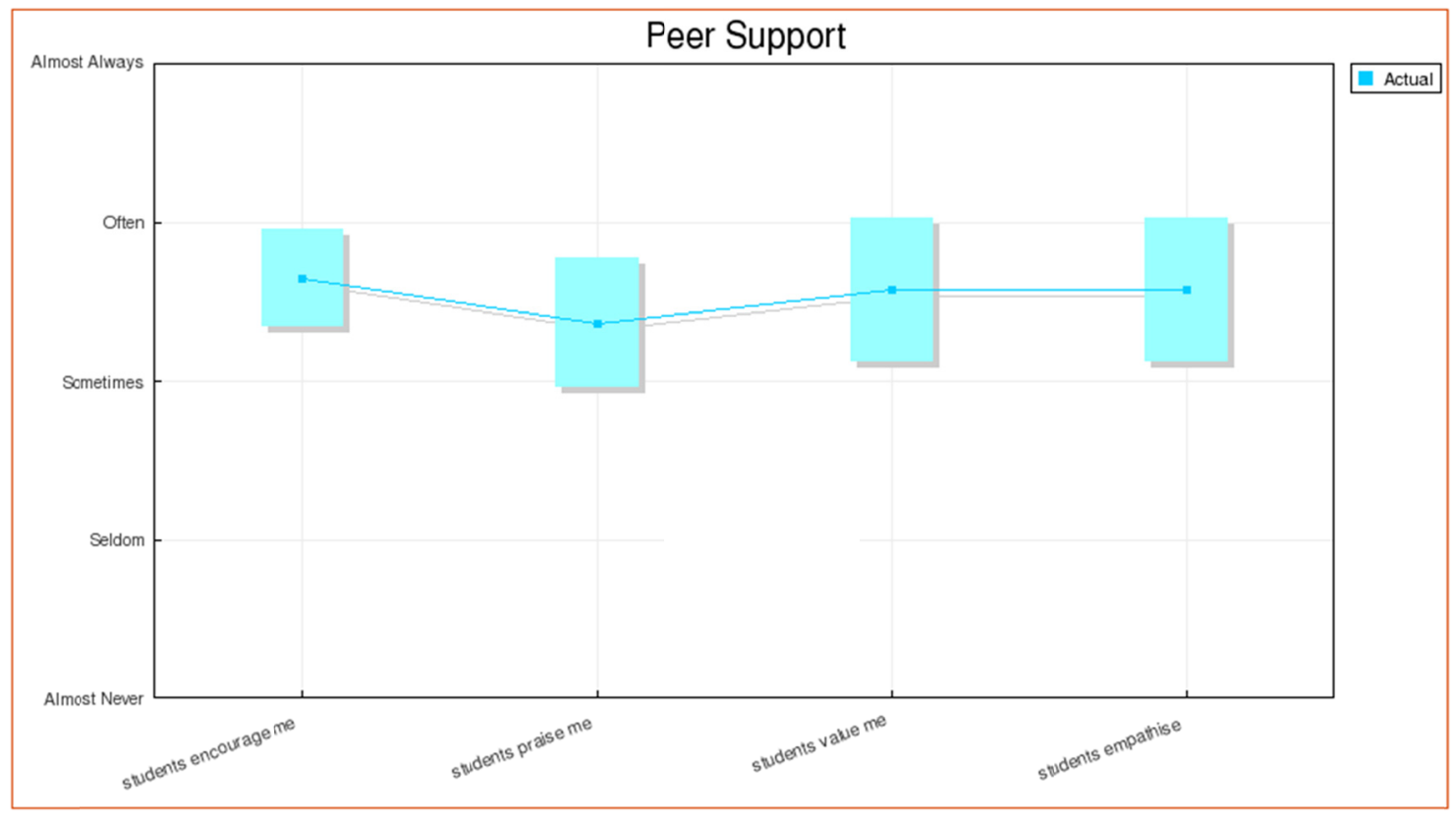

Figure 12. The Scale "Peer Support" of COLLES Research

We conclude that even though they have been encouraged, the lack of praise and feedback may affect negatively their interaction. 


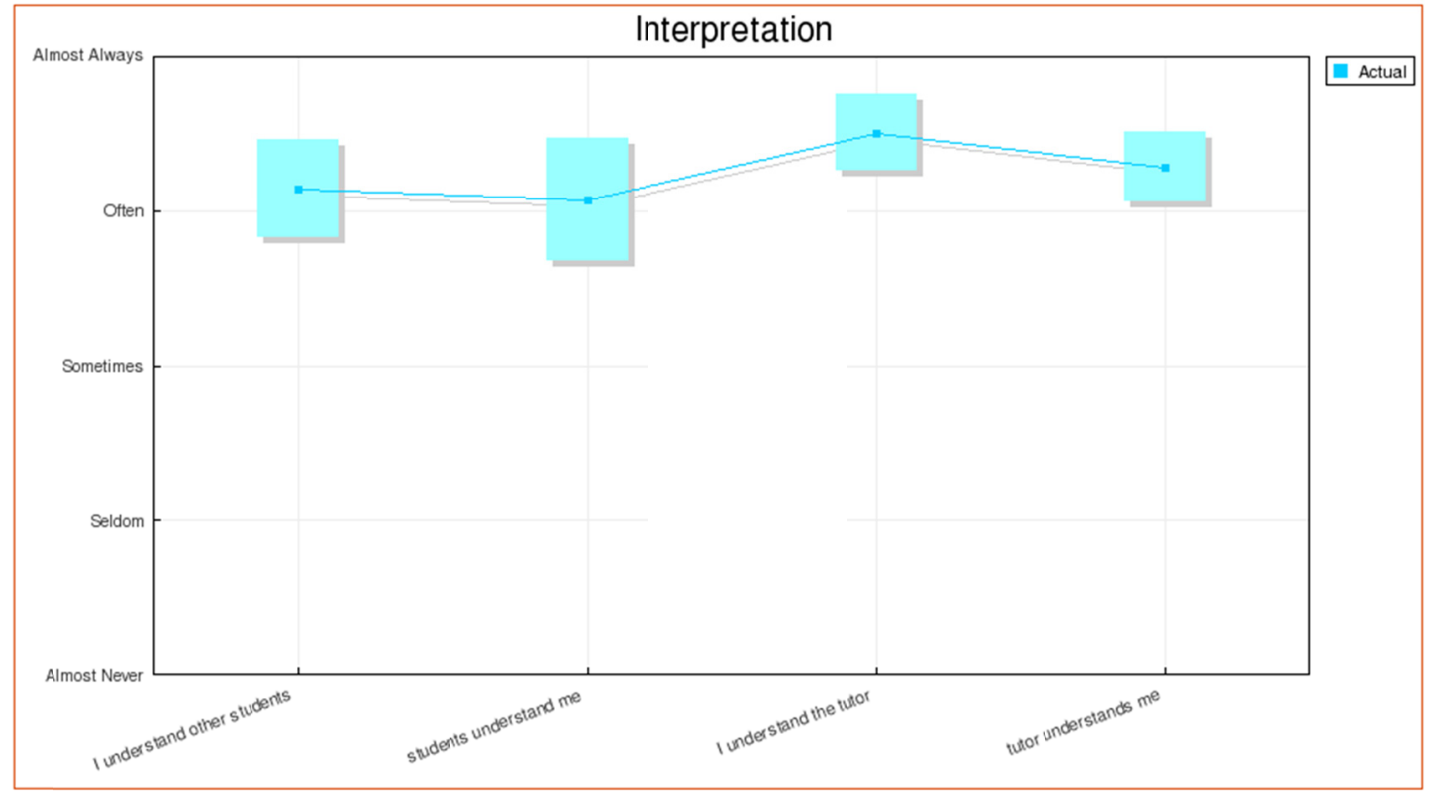

Figure 13. The Scale "Interpretation" of COLLES Research

We conclude high performance, with the exception of lower score of understanding among trainees.

\subsection{Data Collected from Submitted Activities}

During the first week, participants should propose a lesson plan for a lesson about ET. No instructions had been given, just an application form so there were common forms for all participants. Most of the participants did not elicit the misconceptions of their students about ET. In one case of these lesson plans the teacher took into account students misconceptions, he did not use them in a constructivist way in order to eliminate and replace them with the right one scientific options. he just mentioned and told students that these views were wrong. Most participants presented weaknesses of managing scientific issues about evolution, such as the role of environment as an origin for changes, the definition of an adaptation, the definition and the way that a 'theory' constructed in the NoS, the option that organisms follow a teleological evolution, the explanation of natural selection using inappropriate examples (they usually used the examples of the textbook, that in some cases such as giraffes or finches, are not relevant to students' experience), the sexual selection, the evolutionary linkage among human's ancestors, the incapability to teach the evolution as a unifying scientific theory, etc. Most of them faced several difficulties in the context of their school; the chapters about evolution were in the end of the textbook, so not enough time were available for teaching, or during their undergraduate studies they were taught evolution in a high level being unable to transform to school knowledge, or students' were not interested in this subject. The last were noted even when they were asked to describe scientific errors in textbooks or in a dialogue among teachers: most of them were able to describe scientific mistakes, but were unable to teach a school option of the scientific knowledge in their class.

By the end of the third week, they were asked to describe the misconceptions of their students about evolution. Even though in the first week they were able to note only a few of them, they presented a notable improvement: all of them were able to note most of the common misconceptions and connect them with their teaching practice. It seems that during the second and the third week they were provided with the appropriate knowledge to ascertain and manage students' misconceptions. In fifth week they should present a new lesson plan, according to the instructions of the seminar, their proposals were exceptional; a detailed lesson plan, organized according to a teaching strategy taking into account all the principles of constructivism. Moreover, in some cases participants tried to teach evolution theory as a unifying theory, as a fundamental biology principle.

When during the fourth week they introduced themselves in the PCK model, all of them were enthusiastic of its simplicity. In an activity they should propose more components about the PCK. It was notable that all these proposals were part of the PCK model. Teachers used their own terminology and experience, they talked about PCK without even kwon it. They proposed several opinions specially in context component. All these responses show that they were aware of all these issues, but PCK benefited them as an organized model. In their responses they recorded that would like to participate in more training programs about PCK, in order to note the application of PCK model in 
more biological issues, such as genetics, molecular biology, ecology, nutrition, anatomy and physiology.

\section{Discussion - Perspectives}

Our main objective was to organize a training program based on the principles of the PCK. Furthermore, we were able to implement the program remotely, enabling teachers from different regions of Greece to participate. It would be desirable to involve more teachers, so that our results were from a more representative sample, but we managed to draw interesting conclusions.

Both the results from the questionnaire and the final lesson plans submitted show that teachers have benefited from this seminar. They managed to improve various aspects of their teaching, both in scientific and teaching matters and in classroom management issues. All components of PCK, according to their responses, were improved (the average, as shown in Table 5, were near or above 4 with a maximum rating of 5), while comparing lesson plans submitted at the beginning of the course to those tabled at the end, we can see many changes. They engage misconceptions in their teaching, recognize the need of appropriate examples, realize that they need to manage the misconceptions, understand the necessity for a school version of knowledge that will allow them to become more understandable to their students' level. All the participants (100\%) noted that the objectives and expectations of participation in the seminar were fully fulfilled.

Even the comments lodged after the end of the seminar are indicative of participants' benefit: better understanding of the nature of science, be persuaded to teach the evolution as a unifying theory, finding new ideas to improve their teaching, note that improving individual components of PCK can generally improve their teaching, identify weaknesses and improve them, systematize their teaching and organize in an organizational scheme based on PCK.

Most indicators about the organization of the seminar (Table 1) are positive, except of the duration the seminar and the time chosen. The same objection is repeated in the comments submitted by the participants as a proposal for the improvement of the seminar. In the next seminar these two factors should be taken into account, because can increase the number of participants as well as to promote more active participation in the activities and discussions between them. Participants wish to participate in seminars, as an important process in their professional development. But they do participate mainly in face to face seminars as this is what are used to. Seminars like this increases their experience and create positive acceptance in such training programs. Therefore, the e-learning seminars should be well organized and take into account the needs and characteristics of the participants. Beyond their training, aim they to contribute to changing opinions and thus create positive attitudes for lifelong learning through e-learning platforms.

Also in several indicators of COLLES research our seminar achieved high performance (very good performance at the scales "Relevance", "Tutor Support", "Interpretation", a relatively good performance at the scale "Peer Support"). But in scales "Reflective Thinking" and "Interactivity", we see an inability. Correlating this data with the feelings that participants developed (Table 3), we conclude that because of their positive emotions and absence of negative, low performance in research COLLES refer not to their personal weaknesses, but in seminar's failures. Obviously the seminar could not trigger more cooperation, exchange of views, discussion among participants, creative project production among participant groups. This weakness is perhaps reinforced by the finding that there was pressure of time to complete the seminar, as participants had to deal with many activities. So, their priority was their personal development, not cooperation. From the answers about principles of e-learning adopted (Table 4), we see low score in the statements 'Learning by reflection' and 'Learning through case study', confirming the lack of genuine cooperation between participants. Apart from the extension of the duration of the course or the reduction of the requirements for its completion, we will need to include some face-to-face meetings, aiming to have the best acquaintance among participants and develop a team spirit.

Our next goal is to organize a seminar with an increased teacher participation and which will be implied in all aspects suggested by former participants (e.g. the duration, the selection of the period time, the engagement among participants, etc.). But to further retry our hypotheses, teachers who will attend the new seminar, will be monitored when they teach their classes, in order to ascertain their own benefit from the participation will benefit to their students as well.

\section{Conclusion}

We concluded that a well-organized seminar (even through distance learning) could help teachers training. Even more, especially for Evolution Theory (ET) and Natural Selection (NS), we found that improving several 
components of personal PCK of teachers, we were able to provide them with skills to improve their teaching strategies. PCK is an easy to use and acceptable model, that could be used as a framework for even more training programs.

\section{References}

Abell, S.K. (2007). Research on Science Teaching Knowledge. In S.K. Abell, N.G. Lederman (Eds.), Handbook of Research on Science Education, Erlbaum, Mahwah, NJ, pp. 1105-1149.

Akbulut, Y., Kesim, M., \& Odabasi, F. (2007). Construct validation of ICT Indicators Measurement Scale. International Journal of Education and Development using Information and Communication Technology (IJEDICT), 3(3), 60-77.

Barbera, E. (2004). Quality in virtual education environments. British Journal of Educational Technology, 35(1), 13-20. http://dx.doi.org/10.1111/j.1467-8535.2004.00364.x

Berry, A., Loughran, J., \& Van Driel, J.-H. (2008). Revisiting the Roots of Pedagogical Content Knowledge. International Journal of Science Education, 30(10), 1271-1279. http://dx.doi.org/10.1080/09500690801998885

Euridice (2004). Key Topics in Education in Europe. Volume 3. The Teaching Profession in Europe: Profile, Trends and Concerns. Belgium: European Unit. Retrieved 05 October 2016 from http://www.indire.it/lucabas/lkmw_file/eurydice/Key_topics_3_keeping_teaching_attractive_EN.pdf

Hermans, R., Tondeur, J., Van-Braak, J., \& Valcke, M. (2008). The impact of primary school teachers'educational beliefs on the classroom use of computers. Computers \& Education, 51(4), 1499-1509. http://dx.doi.org/10.1016/j.compedu.2008.02.001

Jimoyiannis, A. (2010). Designing and implementing an integrated Technological Pedagogical Science Knowledge framework for science teacher's professional development. Computers \& Education, 55(3), 1259-1269. http://dx.doi.org/10.1016/j.compedu.2010.05.022

Kalogiannakis, M. (2010). Training with ICT for ICT from the trainer's perspective. A Greek case study. Education and Information Technologies, 15(1), 3-17. http://dx.doi.org/10.1007/s10639-008-9079-3

Kaufman, D., Kelly, K., \& Ireland, A. (2008). Supporting E-learning through Communities of Practice. In S. Hirtz \& D. Harper (Eds.) Education for a Digital World: Advice, Guidelines and Effective Practice from Around Globe, Retrieved 03 October 2016 from http://oasis.col.org/handle/11599/52

Kendall, M. (2005). Lifelong learning really matters for elementary education in the 21st century. Education and Information Technologies, 10(3), 289-296. http://dx.doi.org/10.1007/s10639-005-3011-x

Laurillard, D. (2001). Rethinking University Teaching: A Conversational Framework for the Effective Use of Learning Technologies. New York/London: Routledge.

Leonard, M., Kalinowski, S., \& Andrews, T. (2014). Misconceptions Yesterday, Today, and Tomorrow. CBE-Life Sciences Education, 13(2), 179-186. http://dx.doi.org/10.1187/cbe.13-12-0244

Loughran, J., Mulhall, P., \& Berry, A. (2008). Exploring pedagogical content knowledge in science teacher education. International Journal of Science Education, 30(10), 1301-1320. http://dx.doi.org/10.1080/09500690802187009

McDermott, L. (1991). Millikan Lecture 1990: What we teach and what is learned - Closing the gap, American Journal of Physics, 59(4), 301-315. Retrieved 10 November 2016 from https://www.researchgate.net/profile/Lillian_C_Mcdermott/publication/241213640_Millikan_Lecture_1990_W hat_we_teach_and_what_is_learned-Closing_the_gap/links/56266bbe08aed3d $3 \mathrm{f} 1383 \mathrm{e} 72 . \mathrm{pdf}$

Mikropoulos, T.-A., \& Natsis, A. (2011). Educational virtual environments: A ten-year review of empirical research (1999-2009). Computers \& Education, 56(3), 769-780. http://dx.doi.org/10.1016/j.compedu.2010.10.020

Osborne, J. (2003). Literature Review in Science Education and the Role of ICT: Promise, Problems and Future Directions. University of Cambridge: FutureLab.

Paik, S., Zhang, M., Lundeberg, M., Eberhardt, J., Shin, T.-S., \& Zhang, T. (2011). Supporting Science Teachers in Alignment with State Curriculum Standards through Professional Development: Teachers' Preparedness, Expectations and Their Fulfillment. Journal of Science Education and Technology, 20(4), 422-434. https://doi.org/10.1007/s10956-011-9308-1

Rutten, N., Van Joolingen, W. R., \& Van der Veen, J. T. (2012). The learning effects of computer simulations in 
science education. Computers \& Education, 58(1), 136-153. http://dx.doi.org/10.1016/j.compedu.2011.07.017

Salmon, G. (2005). Flying not flapping: a strategic framework for e-learning and pedagogical innovation in higher education institutions, ALT-J Research in Learning Technology, 13(3), 201-218. http://dx.doi.org/10.1080/09687760500376439

Sang, G.-Y., Valcke, M., van Braak, J., \& Tondeur, J. (2010). Student teachers' thinking processes and ICT integration: predictors of prospective teaching behaviors with educational technology. Computers \& Education, 54, 103-112. http://dx.doi.org/10.1016/j.compedu.2009.07.010

Scriven, M. (1991). Evaluation thesaurus (4 ${ }^{\text {th }}$ Ed.). Newbury Park, CA: Sage.

Shulman, L.-S. (1987). Knowledge and teaching: Foundations of the new reform. Harvard Educational Review, 57(1), 1-22. http://dx.doi.org/10.17763/haer.57.1.j463w79r56455411

Stasinakis, P., \& Athanasiou, K. (2012). Greek teachers' attitudes, beliefs, knowledge and context, concerning Evolution Teaching, In C. Bruguière, A. Tiberghien \& P. Clément (Eds.), E-Book Proceedings of the ESERA 2011 Conference: Science learning and Citizenship. Part 3: Teaching and learning science (co-ed. Marisa Michelini and Reiners Duit), (pp. 179-185) Lyon, France: ESERA. https://www.esera.org/media/ebook/ebook-esera2011___Strand3.pdf

Stasinakis, P., \& Athanasiou, K. (2016). Investigating Greek Biology Teachers' Attitudes towards Evolution Teaching with Respect to Their Pedagogical Content Knowledge: Suggestions for Their Professional Development, Eurasia Journal of Mathematics, Science \& Technology Education, 12(6), 1605-1617. http://dx.doi.org/10.12973/eurasia.2016.1249a

Stasinakis, P., \& Kalogiannakis, M. (2015). Using Moodle in secondary education: A case study of the course "Research Project" in Greece. International Journal of Education and Development using Information and Communication Technology (IJEDICT), 11(3), 50-64. http://ijedict.dec.uwi.edu/viewarticle.php?id=2032

Stufflebeam, D.-L. (2003). The CIPP model for evaluation. In D.-L. Stufflebeam \& T. Kellaghan (Eds.), The international handbook of educational evaluation. Boston, MA: Kluwer Academic Publishers. https://doi.org/10.1007/978-94-010-0309-4_4

Treagust, D., \& Duit, R. (2009). Multiple Perspectives of Conceptual Change in Science and the Challenges Ahead. Journal of Science and Mathematics Education in Southeast Asia, 32(2), 89-104.

Van Dijk, E.-M., \& Kattmann, U. (2007). A research model for the study of science teachers' PCK and improving teacher education. Teaching and Teacher Education, 23(6), 885-897. http://dx.doi.org/10.1016/j.tate.2006.05.002

Wenger, E., McDermott, R., \& Snyder, W. (2002). Cultivating Communities of Practice: A Guide to Managing Knowledge. Boston, MA: Harvard Business School Press. 